\section{Anisakiasis: a preventable culinary attack on the gastrointestinal tract}

A 42-year-old woman was admitted to the emergency room because of bilious vomiting and intense epigastric pain. She was unable to tolerate liquids and had moderate signs of dehydration. She had eaten raw fish (sushi) the day before. The patient was hospitalized and rehydrated. She stopped vomiting but the epigastric pain was not controlled. She underwent upper gastrointestinal endoscopy which revealed numerous erosions and ulcers in the gastric body. A parasite with the appearance of an adult Anisakis was found adherent to and penetrating the central part of an ulcer. It was withdrawn with a polypectomy snare. There was a rapid relief of symptoms. The parasitology report identified Anisakis simplex (๑ Fig. 1).

Anisakiasis is related to the ingestion of raw or undercooked fish and occurs in Japanese culture (sushi, sashimi), areas in South America ("ceviche"), Spain ("vinegar anchovies") and the Netherlands (raw fish) [1].

Anisakiasis can become a serious clinical problem when it causes gastric involvement, with ulcerations, pain and, rarely, intramural pseudotumors. Gastric involvement occurs in $90 \%$ of cases. When upper gastrointestinal endoscopy is performed 1 or 2 days after infection, the endoscopic findings are of redness and erosions or ulcerations at the site of penetration of the gastrointestinal wall ( $\bullet$ Fig. 2) [2]. Steroid treatment often solves the crisis, but only expulsion of the worm or its endoscopic removal with a biopsy forceps calms the pain [3] ( Fig. 3). The best solution to anisakiasis in humans is to prevent it by avoiding water contamination and by freezing fish that is to be eaten raw at $-20^{\circ} \mathrm{C}$ for at least 5 days or at $-35^{\circ} \mathrm{C}$ for $15 \mathrm{~h}$.
Endoscopy_UCTN_Code_CCL_1AB_2AD_3AF

\section{Celestino ${ }^{1}$, T. Hirano ${ }^{2}$, R. Sáenz ${ }^{1}$,}

L. Vargas ${ }^{1}$, J. Gobelet ${ }^{1}$

1 The Latin American OMGE/OMED

Advanced Gastrointestinal Endoscopy

Training Center, Santiago de Chile, Chile

2 Center Building Clinic, Nishimachi,

lizuba, Fukuoka, Japan

\section{References}

1 US Food E Drug Administration. Anisakis sp. and related worms. In: FDA-CFSAN Bad Bug Book. Center for Food Safety \& Applied Nutrition; 2003 [cited 2007 July 4]. Available from: http://www.cfsan.fda.gov/ mow/ chap25.html

2 Kakizoe S, Kakizoe H, Kakizoe K et al. Endoscopic findings and clinical manifestation of gastric anisakiasis. Am J Gastroentero 1995; 90: 761 - 763

3 Ramos L, Alonso C, Guilarte M et al. Anisakis simplex-induced small bowel obstruction after fish ingestion: preliminary evidence for response to parenteral corticosteroids. Clin Gastroenterol Hepatol 2005; 3: $667-$ 671

\section{Bibliography}

DOI $10.1055 / \mathrm{s}-2007-966831$

Endoscopy 2007; 39: E312

(c) Georg Thieme Verlag KG Stuttgart · New York . ISSN 0013-726X

\section{Corresponding author}

\section{R. Sáenz, MD}

The Latin American OMGE/OMED Advanced Gastrointestinal Endoscopy Training Center Clinica Alemana-Olympus

Universidad del Desarrollo

Vitacura 5951

Santiago

Chile

Fax: + 56-2-210-1478

rsaenz@alemana.cl

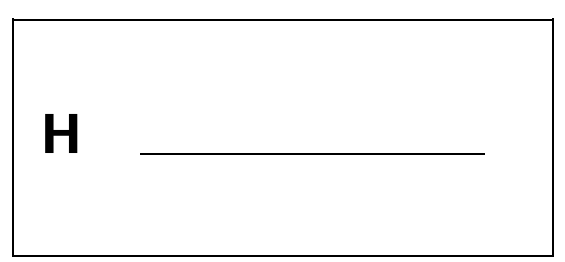

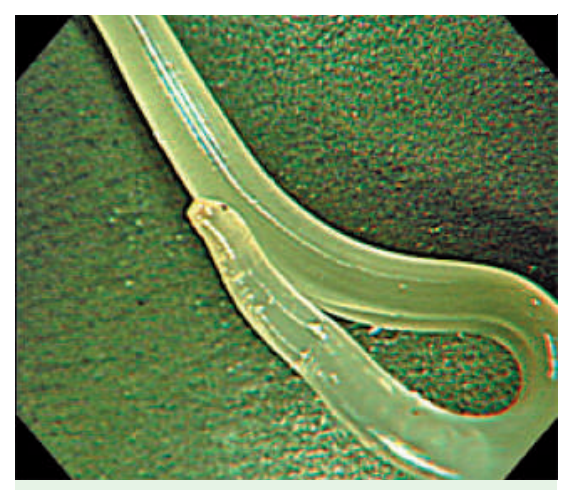

Fig. 1 Anisakis parasite as seen by magnification endoscopy.
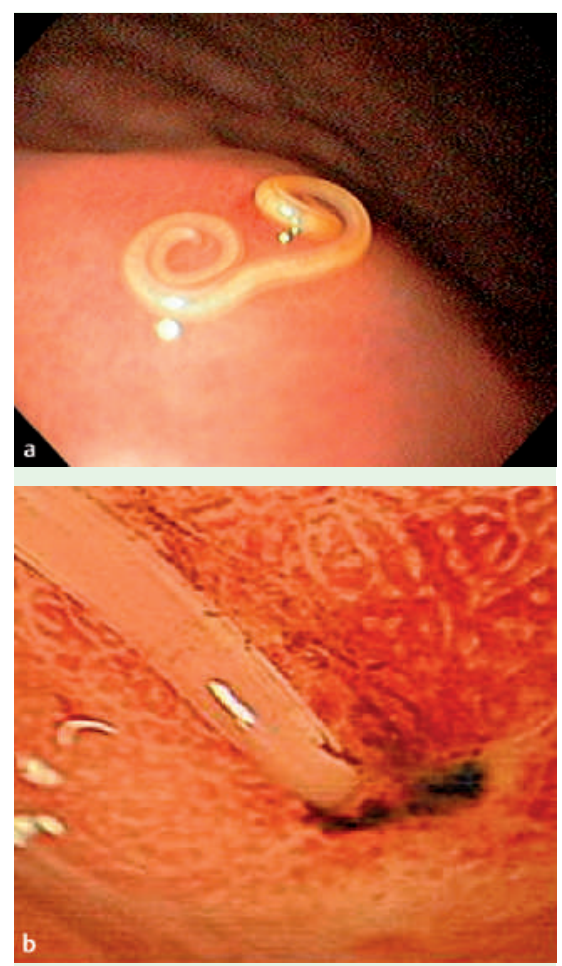

Fig. 2 a Anisakis parasite penetrating the gastric mucosa. b Magnification endoscopy image.

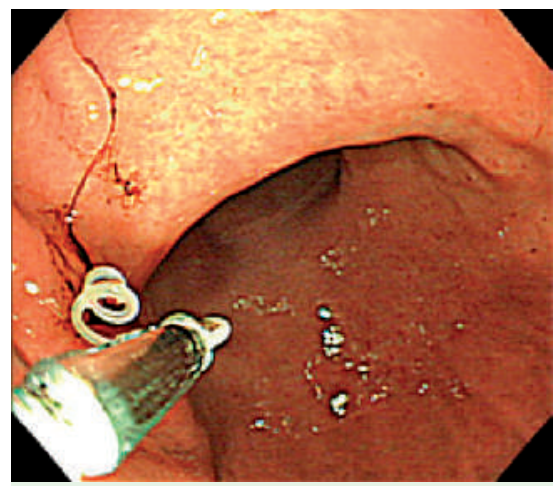

Fig. 3 The Anisakis worm was removed using a polypectomy snare. 